\title{
Educational Exigencies of the 21st Century: Implications for Teacher Education Programs in East Africa
}

\author{
Peter Kajoro \\ Lecturer, Aga Khan University, Institute for Educational Development, East \\ Africa \\ Hellen Nabututu Chirure \\ Irene Simiyu
}

\begin{abstract}
Questions about what constitutes effective teacher education, compatible with today's changing educational demands, have become commonplace. This article is therefore an overview of ideas about the elements of effective teacher education in light of the $21^{\text {st }}$ century demands. Drawing on literature and the authors' knowledge of teacher education in the East African context, the article argues the case for the different elements of effective teacher education programs that would help the region, and by extension other developing countries, meet their educational obligations in the $21^{\text {st }}$ century. The paper also highlights the theoretical underpinnings of these elements and concludes with the implications of these elements to teacher preparation in East Africa.
\end{abstract}

Key words: Effective Teacher Education; $21^{\text {st }}$ Century Education; East Africa

\section{Introduction}

Both teacher preparation and the role of the teacher as a facilitator of learning in the 21 st century educational systems have come under scrutiny to establish if they are compatible with the rapid and diverse changes taking place in the world today. Therefore, the assertion that an education system is as good as its teachers (Basaza, 2006) or that the teacher is the single most important factor in determining a student's achievement (Obama, 2006) must be located within the framework of this ongoing scrutiny.

While acknowledging the crucial role that teachers ought to play in the education of the young, MacLeod (2007) extrapolates Obama's assertion to say that since the quality of our teachers is determined, to a large extent, by the quality of the teacher education programs (TEPs), then improving the quality of teachers neatly translates into first improving the quality of TEPs. Consequently, the most important challenge for governments in improving their education systems would be that of ensuring that they put in place well-functioning TEPs that would produce well trained and competent teachers. This is definitely a complex and uphill task considering that learning to teach is a multidimensional process (Ngondu, 2010) that needs substantial investment, both fiscal and temporal, in order for participating student-teachers/teachers to acquire the 
required competences.

The East African education context has not escaped this scrutiny. Currently the context is facing challenges brought about by Education For All (EFA) which has raised the demand for quality, quantity and relevance in teacher education to ensure education quality in graduating student-teachers or practicing teachers who would in turn improve student achievements in tandem with the 21st century definition of education as an instrument of producing individuals capable of technological innovations, sound moral choices, entrepreneurial dominance and survival in the world today and in future (Townsend \& Bates, 2007). TEPs, which are defined as interventions for candidate teachers or practicing teachers, therefore need to change to keep pace with the times and to squarely address their inadequacies. As Guskey and Huberman (1995) observe, "effort must be made to correct ... inadequacies if education institutions are to meet the demands of our increasingly changing society" (p. 1). This opens a debate on what elements make an effective TEP that would equip the teacher of the 21st century with competences and skills to produce learners who are able to transform the world (Darling-Hammond, 2000; Good \& Brophy, 2008). It is against this backdrop that this article reviews the current practice of TEPs in the East African region, and literature on what should constitute an effective TEP that would meet the exigencies of the 21 st century in a developing world context.

It should be noted that although the East African region currently consists of five countries after Burundi and Rwanda joined the East African community, this article will focus its discussion only on Kenya, Tanzania and Uganda, the three countries which initially formed the East African community.

\section{East African Educational Context}

Before embarking on a discussion of the TEPs in East Africa, which is the focus of this paper, it would be quite in order to discuss the local educational context first so as to provide the contextual framework within which to locate the TEPs that furnish the teaching force in all schools in the region.

Kenya has followed the ' $8-4-4$ ' structure since 1985. This means 8 years of primary schooling, 4 years of secondary education, and 4 years college/ university. Kenya's language of instruction policy may be gleaned from what Kobia (n.d) writes in this regard:

The language policy in the education system in Kenya is that English is supposed to be the medium of instruction, except in Kiswahili subject in Primary school for Standard one to eight. Mother tongue is assigned the language of instruction for lower primary, class one to three. However, this is in theory because in practice, especially in rural areas, some schools use mother tongue with a mixture of Kiswahili and English as a medium of instruction even in class eight. (p. 81)

Note that class eight marks the end of the primary school cycle. In the last sentence of the quote above the author is actually lamenting about the use of a mixture of mother tongue, Kiswahili and English at the end of the cycle and in that way seems to be drawing the reader's attention to the ineffectiveness of teaching the requisite language of instruction, English. The assignment of mother tongue to the teaching of lower primary has to be looked into cognizant of the 
fact that Kenya has 42 ethnic groups (Thuranira, 2010), each with its own mother tongue. Teacher training in Kenya takes place in training colleges and universities. There are eighteen public primary teacher colleges in Kenya. Trainees must be holders of the Kenyan Certificate of Secondary Education (KCSE), that is, graduates of the 4-year secondary cycle, having scored an average of C (Thuranira, 2010). Upon completion of the two-year training, these teachers teach in primary schools. Thuminira (ibid) identified two levels at which secondary school teachers are prepared: at university, for those majoring in education at undergraduate level for four years; or in diploma teacher colleges for holders of KCSE with three years training.

Tanzania follows the 2-7-4-2-3+ structure of education. This consists of: two years of pre-school education; seven years of primary education; secondary education which has two components, ordinary level (O-level) and the advanced level (A-level), which require four years and two years; and post-secondary education including university undergraduate programs, that take three or more years. SACMEQ (2012) reported that there were far more pre-primary institutions in urban areas than there were in rural areas. The language of instruction is Kiswahili, the national language, and English. Most of pre-school education managed by private institutions is provided in English. At Primary school level, the language of instruction is officially Kiswahili but there are also quite a substantial number of primary schools that teach in English. Swilla (2009) reported the following about language of instruction in primary schools and its distribution in private and public primary schools:

There were 1,500 primary schools in Tanzania in July 2008, of which 503 were private and 997 were government schools. Four government and 480 private primary schools use English as LoI. Thus only $32.26 \%$ of the total primary schools in Tanzania use English as LoI and $67.74 \%$ are Swahili-medium. However, the majority of English-medium schools $(95.42 \%)$ are private while the government owns the majority of Swahili-medium schools (88.97\%). Taking each group separately, $99.17 \%$ of private primary schools are English-medium and $99.59 \%$ of government schools are Swahili-medium. Therefore, private primary education is synonymous with English-medium, and government primary education, with Swahili-medium education. (p. 5)

The official language of instruction at secondary school level is English, although code switching between English and Kiswahili is actually the order of the day given the fact that the majority of both teachers and students do not have a mastery of the English language (Qorro, in Brock-Utne \& Holmarsdottir, 2004).

According to SACMEQ (2012) there were 41 teacher colleges with a total enrolment of 12,296 teacher trainees in Tanzania in 2002. The colleges provide teacher education at diploma and Grade A levels. Diploma trainees are prepared to teach in secondary schools (Ordinary level only) and in grade A teacher education colleges while Grade A trainees are earmarked to teach primary and pre-primary schools. A-level teachers can only be university graduates who majored in Education. The colleges also provide in-service training to teachers who wish to upgrade themselves from lower grades (Grade C or B) through residential training and distance learning. Grade A certificate trainees are normally recruited from O-level graduates whilst diploma trainees are recruited from among A-level graduates. Universities, both public and private, also train 
teachers who teach at the two cycles of secondary education and in teacher education colleges. Mhaiki (2009) posited that although the Teacher Education Diploma Curriculum for Secondary Education requires that tutors who teach at Diploma Teacher colleges be holders of Master's degree with at least a five-year experience of teaching at secondary school level, diploma teacher education colleges are awash with tutors holding an assortment of qualifications including some who have come in directly from secondary school studies.

The Ugandan educational system follows the 2-7-4-2-2+ structure, which has been in place since the release of Uganda's Castle Commission report (1963). It consists of seven years of primary education, followed by a four-year cycle of lower secondary (O-level), a two-year cycle of upper secondary (A-level), after which there are two to five years of tertiary education. There is also a two-year pre-primary stage of education attended by three to five year olds before joining primary school (SACMEQ, 2011)

The language of instruction in all subjects from Primary four onwards is English in all schools in Uganda (Kendrick, Jones, Mutonyi \& Norton, 2006). The language of instruction policy in Uganda directs that all lower primary education (that is primary one to three) be in local languages. In a country that in 1999 identified 63 local languages that could possibly be used as languages of instruction serving different ethnic groups, some without any established orthographies and trained teachers in those language (Penny; Ward; Read,\& Bines, 2008), teaching in local languages becomes a very challenging task indeed.

There are two types of teacher training colleges offering TEPs: Primary Teacher Colleges, which recruit trainees from lower secondary graduates to become primary school teachers; and National Teacher Colleges which recruit trainees from upper secondary graduates to become secondary school teachers. Another important source for secondary schools teachers is the university. University graduates who have majored in education can teach both O-level and A-level.

\section{Overview of TEPs in the East African Region}

TEPs in the East African region have been criticized for being deficient in many ways. In Kenya the university teacher education course, according to Ong'ndo \& Borg (2011), lasts for four years consisting of a course work component and 12-week practicum that is supervised by an examiner who is not necessarily an expert in the student teacher's subject. In Uganda, a typical teacher education curriculum consists of subject matter domain, foundations for education, professional studies and the practicum as distinct parts (Aguti, 2003). This shows that content, pedagogy and pedagogical content knowledge are not integrated. This scenario is replicated in both Kenyan and Tanzanian teacher education curricula. Like Kenya and Tanzania, Uganda has a practicum component, but this is done for a limited period and is not closely supervised or monitored by the teacher educators (Basaza, 2006). Secondly, the presentation of theory is either too early or too late in view of its relevance to the teaching practicum (Ibid).

According to the Centre for Children's Rights (Kuleana) report (1999) the training of teachers in Tanzania continues to be inadequate and fraught with problems. Like Kenya and Uganda, candidates are typically selected from those unable to obtain admission for further schooling or in other professional fields. Kuleana reports that teachers are often inadequately prepared and lack basic skills 
in teaching methodology, class management and counseling. The report attributes this to a combination of poor basic educational preparation of teachers and inadequate resources in teacher education colleges. In addition, according to the Tanzania's Ministry of Education and Vocational Training (MOEVT) (2007), the high demand for teachers has led to adoption of strategies such as; conducting short courses for successful secondary school advanced level leavers, to get into the teaching profession as well as hurried conversion of a teacher education college and a secondary school into constituent teacher education colleges of the University of Dar es salaam to increase the supply of teachers. This has in effect compromised the quality of teacher education in Tanzania. However, Tanzania has in the recent past reviewed her teacher education curriculum to meet the emerging challenges. For example, until 2007, the diploma TEPs did not include the subject content component but due to complaints from stakeholders about the non-inclusion of academic subject content the ministry of education revised the curriculum and brought back the content component (MOEC, 2007). At the same time, MOEVT reviewed the teacher education curriculum to be in tandem with the shift from content-based to competence-based learning that had been introduced in both primary and secondary schools. According to Mhaiki (2009), despite the new curriculum incorporating a paradigm shift from the teacher-centered model to a reflective-practitioner inquiry-based model, little attention was given to empowering teacher educators with the knowledge and skills required to implement the new model. In addition, the content of the revised diploma TEP is divided into two distinct parts, professional studies and subject content, which are taught as separate entities. Also revised was the timeframe for field based practice, from one month to nine months, during which period the teacher trainees are expected to work under mentors and develop teaching portfolios. It appears that Tanzania is way ahead of the other East African countries in the review of TEPs. Even so, this curriculum review has only affected the diploma TEPs, as the universities have not taken cue.

In the Kenyan context, TEPs incorporate both theory and practice, since one of the objectives of teacher education is "to develop basic theoretical and practical knowledge about the teaching profession, so that the teachers' attitudes and abilities can be turned towards professional commitment and competence" (Kenya Institute of Education, 2004 p. ix). However, the actual teaching involves more theory with little emphasis on inquiry learning and a short practical teaching experience. While no TEP can prepare teachers adequately for all the situations they will encounter in their profession (Townsend \& Bates, 2007), the resulting gap between theory and clinical experience leads to teachers who are unprepared for the challenges of teaching.

Considering the limitations of current TEPs in the East African region, the sections that follow will discuss elements which are believed to be vital for a 21 st century TEP in the region.

\section{Elements of an Effective Teacher Education Program}

\section{Information and Communication Technology (ICT)}

Perhaps the most striking exigency of the 21 st century is information and communication technology (ICT). ICT is expanding rapidly in this century and according to UNESCO (2002), teacher education institutions have either to assume a leadership role in the transformation of education or be left behind in 
the swirl of rapid technological change. Inoue and Bell (2006) contend that webbased learning, e-learning, technology-mediated learning and technologyenhanced learning are a reality of today's educational systems. ICTs have the ability to transform the nature of education, where and how learning takes place, and the roles of students and teachers in the learning process (JanssensBevernage, Cormille \& Mwaniki, 2006; Thorsen, 2006). This is especially necessary because the 21 st century learner is technology savvy. The implication for teachers is that they should be knowledgeable to offer guidance to their learners, as well as explore those aspects of technology that will enhance their content delivery. Consequently, teacher education programs need to focus on practical application of ICTs, as teachers need new understandings of the pedagogies appropriate to the 21st century (Forde, McMahon, Mcphee, Patrick, 2006). As Collin \& Jung, cited in Jung (2005) observe, teachers are likely to integrate ICT in their teaching if they experienced ICT skills as learners.

The East Africa governments are in the process of making internet reception available to all parts of the region. The wider availability of internet connectivity (assuming East African countries can afford other ICT-related infrastructure) means that TEPs will have both the opportunity and responsibility to explore new approaches to teaching and learning.

In Tanzania, the national ICT policy in education gives prominence to the use of ICT as a pedagogical tool for teaching and learning, and for professional development of teachers (Wamakote, Ang'ondi \& Onguko, 2010). This is perhaps the reason why ICT was introduced in diploma TEPs in 2006 (MOEVT, 2006). However, Bakari (2010) observes that the current teacher education curriculum does not integrate the ICT component in a college subject; instead it is taught separately. Similarly, apart from those teachers who are being prepared specifically to teach ICT as a subject, research in Kenya by Wim and Lawler (2007) shows that TEPs have not made much provision for ICT for all teachers. Where effort has been made, the emphasis has been on building teachers' understanding of ICTs rather than preparing them to teach with ICTs. This is despite there being a national ICT policy that recommends the promotion of ICT in education by ensuring that teachers and teacher trainers possess the requisite skills (Wamakote, Ang'ondi, \& Onguko, 2010). There needs to be a "shift from learning about ICTs to learning with and through ICT" (SEED, 2005, p. 8). This shift is expected to produce ICT literate teachers and a versatile, adaptable teaching workforce that is consistent with the human capital theory of education (Hawkins, 2002; Wamakote, Ang'ondi, \& Onguko, 2010).

ICT in Teacher Education Programs is informed by the cognitive and social constructivism learning theories that support student-centered approaches. Inoue and Bell (2006) contend that ICT will facilitate the move from passive learning to active learning, which is the current thinking that advocates for learner autonomy and life-long learning. Incorporation of ICT in teacher education programs will however have to go hand-in-hand with the establishment of a sustainable ICT infrastructure in schools where the graduates of these programs will eventually work. If, for instance, governments in the East African region do not seriously and immediately embark on large scale electrification projects of their rural areas or work towards acquiring ICTs that may very effectively function on other energy sources such as solar energy, the otherwise promising dream of enhancing learning outcomes among learners through the use of ICT in TEPs will remain a utopia. Concerted efforts will therefore be required of all the governments of the region to ensure that student teachers who learn with ICT 
are technically and pragmatically empowered to teach with ICT in all teaching and learning settings.

\section{Intensive and extensive hands-on experience}

Another important element of an effective TEP is that it should not just incorporate but emphasize intensive and extensive hands-on experience to provide students with opportunities to encounter real life issues that they are likely to encounter in their future teaching practice (Darling-Hammond, 2006). Hands-on experience refers to the practical experience of teaching in a real or simulated classroom. It is also referred to as practicum or clinical experience. This is especially important because in East Africa, like most of the developing world contexts, the majority of learners is from challenging backgrounds and has therefore diverse learning challenges that require teachers to continually adapt their teaching to suit them (Knowles, in Rudney \& Guillaume, 2003). Moreover, there is an increasing emphasis on inclusive classrooms in the 21st century, where teachers adapt their teaching styles to suit the range of diversity that is found among children in any class (UNESCO, 2001). Yet research shows that few TEPs actually provide teachers with practical classroom skills (Darlin, 1998). Both novice and experienced teachers often complain that learning experiences inside the classroom are too removed from the realities to have a meaningful impact (Putman \& Borko, 2000). Belmonte (2003) captures this in his reflection:

In university methodology classes, I was thunderstruck by the unending desire of prospective teachers for answers to 'what if ' questions. The gulf between the theoretician and the practitioner could not be wider than in this area. (p. 62)

The inadequacies of the practicum component of TEPs in the East African region are very similar to the gaps identified above. Addressing practicum inadequacies calls for teachers' learning that is intertwined with extensive practice, so as to influence and support their practice in meaningful ways. Gough (1997) agrees that significant growth can never be based on transmission or delivery of facts and information alone. The assumption here is that by undergoing an extensive clinical practice, teachers will develop an appreciation of their job and learn how to reflect and find solutions to issues.

In the three East African countries, initial teacher preparation involves relatively short periods of hands on experience in both simulated and real environments due to funding constraints. This is, however, further exacerbated by the ineffectiveness of supervision. In Tanzania, like in Kenya and Uganda, TEPs include a practicum component, that is however, not implemented effectively. For example, the DANIDA report (1996) indicates that many teachers in Tanzania graduate without fulfilling the practical teaching component due to lack of funding. In Kenya, the hands-on experience in the form of 'teaching practice' is on average only 3 months; and from the authors' knowledge, this is neither intensive nor extensive and inadequately supervised.

One way to provide intensive and extensive hands-on experience is through the use of clinical schools. These are sites for 'state of the art' practice in inclusive classrooms that are organized to support training of both new professionals as well as professional development of experienced teachers. Although clinical schools may not cater for the contextual differences of various 
classrooms, it provides an opportunity for skills to be practiced, refined and internalized in an inclusive classroom. What is more, Allen and LeBlanc (2005) point out that teachers who have a clinical experience are more engaging, reflective, thoughtful and effective. They are, therefore, likely to remain in the teaching profession and strive to improve their practice. This is perhaps because the hand-on experience allows them to experience some of the 'real' challenges of teaching and seek solutions supported by peers and teacher educators. The assumption here is that adult learners learn best when the subject is of immediate use.

Situated learning theorists assert that how a person learns and the situation in which a person learns become a fundamental part of what is learnt (Putman \& Borko, 2000). A focus on the situated nature of cognition suggests the importance of authentic activities in the teacher education classroom. Authentic activities in this case are activities that are similar to what actual practitioners engage in. This also supports Brunner's constructivism theory, which argues that authentic experiences provide learners with opportunities to construct knowledge and ensure retention (Pritchard, 2005).

\section{Integration of content, pedagogy and pedagogical content knowledge}

It is important that effective TEPs focus on the integration of content, pedagogy and pedagogical content knowledge. However, Bransford, Brown \& Cocking (1999) give research evidence that many teacher education programs fall short of this ideal. Pre-service programs in the East African countries tend to focus on content and pedagogy as separate units, rather than on the need to integrate pedagogy with the content of various disciplines. To make matters worse, teacher educators at universities in Kenya and Tanzania are not necessarily themselves qualified teachers, and may lack pedagogical knowledge and pedagogical content knowledge. This inadequacy is also evident in TEPs in the developed world contexts. For example, the National Commission on Teaching and America's future (1996) identified the problems with TEPs as: inadequate time to learn subject matter and nature of learning, fragmentation of courses, uninspired teaching methods, and superficial curriculum, with little depth in subject matter.

Bransford, Brown \& Cocking (1999) state that teachers need to understand subject matter deeply in order to help learners create useful cognitive maps, relate ideas and address misconceptions. The assumption is that a teacher who is knowledgeable in the subject matter will find it easy to integrate theory with practice. Secondly, knowledge of the subject matter and appropriate instruction is likely to win the learners confidence and thus impact positively on the learning outcomes.

\section{Inquiry-based learning}

An important characteristic of an effective TEP is inquiry-based learning (IBL) that encourages reflection and action research. This is to enable teachers to deal with the challenging classroom situations in todays' classrooms. In addition, educational researchers are constantly discovering new knowledge about teaching and learning processes; and as this professional knowledge base expands, new types of expertise are required of educators (Guskey \& Huberman, 1995). Stallworth (1998) contends that teachers' greatest opportunity for systematic growth is systematic inquiry into their own teaching. An effective 21st 
century TEP should therefore equip future teachers with the skills of reflection, critical inquiry, problem solving and educational research, to ensure that teachers can learn anything they want to learn when they want to learn it. The assumption here is that teachers equipped with IBL skills are likely to question their practice systematically and locally develop answers, instead of waiting for an 'outsider' to suggest what should be done. Ponte (2005) aptly captures our argument - that it is only teachers who will change the world of school by understanding it as 'insiders'.

One way in which TEPs can encourage teacher inquiry is through reflective practice. Sachs (2003) concurs that "one of the primary outcomes of any TEP should be educating intellectual and reflective practitioners" (p. 64). In fact, a TEP that seeks to prepare teachers for life-long learning should not miss out on the reflection component that allows teachers to learn from their teaching practice. Action research is another example of inquiry approach to enhancing teacher education. Student teachers could be required to engage in this practice during the course so as to reveal its future practicability. Action research involves a systematic inquiry into classroom practice with the intention of solving an educational problem (Hendricks, 2006). Bransford, Brown and Cocking (1999) observe that action research contributes to sustained teacher learning and encourages and increases the professional standing of teachers by recognizing their ability to add to knowledge about teaching. We believe that training in inquiry helps teachers learn how to look at the world from multiple perspectives and to use the knowledge to build pedagogies that can improve learning. The assumption we are making here is that teachers who learn to be teachers by inquiry are more likely to transfer the same skill to their learners and thus improve the quality of teaching and learning in the schools.

As the old adage goes, "experience is the best teacher". However, emerging educational issues in the East African context such as students' unrest, caused by anxiety over exams as well as other factors, need systematic inquiry and not just experience. We therefore concur with Good and Brophy (2008) that while experience is a necessary condition for learning and improving practice, it is not a sufficient condition. Professionals must strive to understand their practice through systematic inquiry. People learn best when they make discoveries and reflect on them, rather than blindly imitating others (Pritchard, 2005). Constructivist theories emphasize discovery learning, and learners as creators and thinkers (ibid). We hope that inquiry-based learning will produce teachers who are able to engage in inquiry in their practice and therefore, be able to meet the changing demands of 21 st century education.

\section{Authentic on-going assessment}

An effective TEP should encompass authentic on-going assessment because there is increased emphasis by educationists in the 21 st century on the value of learners being able to apply knowledge (Jones, 2007). It is widely accepted that rote-learned knowledge is easily forgotten and may not be useful in handling emerging issues. However, assessment in the TEPs in the East African context is mainly summative and involves paper and pencil tests. The USAID/UNITY (2007) project handbook for certificate in teacher proficiency courses in Uganda criticizes the current assessment practices in teacher colleges as being narrowly focused on the cognitive domain. In addition, summative assessment does not allow opportunities for immediate remedies that will allow engagement with 
knowledge and thus retention of information. This scenario is replicated in the other East African countries. Paper and pencil tests have been criticized for not adequately testing higher levels of thinking and for not testing the ability to apply knowledge in real life.

Environments that have inbuilt on-going authentic assessment provide opportunities for learners to test their understanding by trying out ideas and receiving feedback. Such opportunities are important to teacher education for a number of reasons. First, teachers often do not know if certain ideas will work unless they are prompted to try them with students and see what happens. Secondly, feedback on authentic tasks provides opportunities to clarify ideas and correct misconceptions so that they are not carried over into practice (Bransford, Brown \& Cocking, 1999). The inclusion of authentic on-going assessment would facilitate the testing of application of knowledge and therefore, hopefully produce teachers who are not only knowledgeable but are able to apply knowledge in a real context. Besides, it is assumed that these teachers are more likely to engage their own learners in authentic assessment if they themselves experienced it first hand, thus improving the quality of assessments for and of learning in schools.

\section{Collaborative and learner-centered approach to learning}

Teachers in the East African context are faced with the daunting task of handling vast amounts of knowledge, demands for good results from parents and Ministry of Education officials, and learners who have diverse personalities, but who must be facilitated to reach the highest levels of education. This may lead to what Darling-Hammond (2006) views as a teacher who is overworked, frustrated and lacking support from fellow teachers, and simply struggling in their job. The authors' experience in the region bear testimony to the fact that the current TEPs in the East African context could be blamed for this, for they do not prepare teachers to find help among themselves, as they make little use of peer socialization, perpetuate isolation and individualism which works against collegiality and career-long learning. An effective TEP should emphasize collaborative participation of teachers in learning activities, as opposed to teaching individual teachers. This could perhaps mean that teachers may be able to work together with others in communities in which members network and share issues affecting their profession.

Effective TEP should incorporate a learner-centered approach to teaching. Environments that are learner-centered attempt to build on strengths, interests and needs of the learner. It is important to note that teachers do not come to TEPs as empty vessels but bring along experiences, practices, and insights about the profession. Collaborative learning in TEPs is informed by a principle of adult learning: that adults prefer to operate in collegial environments that allow them to bring extensive life experiences to enhance new learning (Knowles, in Rudney \& Guillaume, 2003). Teachers who connect with others in their school or vicinity, in what Jung (2005) calls larger teaching communities, realize that the challenges they face are not unique to their context and they can get support and understanding from other like-minded people.

The foregoing discussion about the elements of effective TEPs have far reaching implications to the nature of TEPs in the East African region in terms of how they will have to be delivered, their scope and content. 


\section{Implications for teacher preparation in East Africa}

First, curriculum developers of TEPs need to review current teacher education curriculum in the East African countries with the view of enhancing quality. This calls for creation of courses that will prompt student teachers to be more analytical of their practice and to take charge of their own professional growth once they begin practice. The curriculum should also emphasize intensive handson minds-on experience in authentic environments besides emphasizing collaborative and learner-centered approach to learning of content. The integration of ICT as well as content, pedagogy and pedagogical content knowledge need to be reinforced in the curriculum.

Secondly, teacher educators need re-orientation on the best practices in teacher preparation especially in the area of content delivery and assessment as well as integration of ICT and use of ICT resources in the classroom. Teacher educators with a strong knowledge base are a necessary condition for effective delivery of TEPs. There is also need to review the recruitment of teacher educators to ensure that only those with a foundation of pedagogical and pedagogical content knowledge are recruited.

\section{Conclusion}

This paper began by highlighting the importance of adjusting East African education systems to the rapidly changing world of the 21 st century. A discussion of elements of effective TEPs that meets the exigencies of the $21 \mathrm{st}$ century then followed, exploring the important characteristics of such TEPs. These characteristics were identified as: inquiry-based learning; hands-on experience; the use of ICT; and integration of content, pedagogy and pedagogical content knowledge. In addition, TEPS should include on-going authentic assessment with a collaborative and learner centered approach. We believe that these elements will provide teachers with knowledge for practice, knowledge of practice, and knowledge in practice, which will translate into improved learning outcomes for the student teachers. The arguments for the elements of an effective TEP presented here have various implications for teacher preparation in the developing world including teacher education curriculum review that will witness an overhaul of the current content to make way for, among many others, the inclusion of ICTs in TEPs and introduction of an extensive and intensive hands-on practicum.

Lastly, to incorporate and implement an effective TEP requires funding. This has implications for governments and education sector stakeholders who need to provide more funding for teacher preparation in terms of infrastructure development, teacher educators' capacity building and related resources. It must also be borne in mind that inclusion of all the elements of effective teachers' professional learning listed above will not by themselves guarantee the transformation of the quality of teaching in our classrooms. Governments need to take drastic steps to review the teachers' working conditions including remunerations so that teachers can focus their attention solely on the teaching and learning process rather than divide their time and attention between teaching, offering private tuition, and engaging in small scale businesses to make ends meet. 


\section{References}

Aguti, J. (2003). Conceptualization and contextualization of distance education. Unpublished doctoral dissertation, University of Pretoria, Pretoria, South Africa.

Allen, D. W., \& LeBlanc, A. C. (2005). Peer coaching that improves instruction: The 2+2 performance appraisal model. Thousand Oaks: Corwin Press.

Bakari, I. (2010). The use of ICT in teaching and learning in public teachers colleges. In UNESCO National Commission of the Republic of Tanzania. Tanzania and UNESCO magazine. No. 6. 2009-2010.

Basaza, N. G. (2006). Distance education and realistic teacher education pedagogy in Uganda: Implications of an ICT supported learning environment. A PhD thesis, University of Ghent, Belgium

Beattie, M. (1995). Constructing professional knowledge in teaching: A narrative of change and development. New York: Teachers College Press.

Belmonte, D. (2003). Teaching from the deep end: Succeeding with today's classroom challenges. London: Corwin Press.

Bliss, T. J., \& Bliss, L. L. (2003). Attitudinal responses to teacher professional development for effective integration of education technology. Journal of In-service Education: An International Journal of Professional Development, 29(1), 81-99.

Bransford, J .D., Brown, A. L., \& Cocking, R. R. (Eds.). (1999). How people learn. Brain mind, experience and school. National Academy of Sciences.

Brock-Utne, B. Holmarsdottir, ; H.B. (2004) International Journal of Educational Development 24, 67-83

Centre for Children's Rights (Kuleana) (1999). The state of education in Tanzania. Dar es Salaam

DANIDA (1996). Project evaluation report, Primary education program (PEP) Tanzania.

Darlin, P. (1998). School development: Theories and strategies. London: Continuum.

Darling-Hammond, L. (2000). How teacher education matters. A Journal of Teacher Education, 51(3), 166-173.

Darling-Hammond, L. (2006). Constructing a 21st Century teacher Education. Journal of Teacher Education, 57(3), 300-314.

Forde, C., McMahon, M., Mcphee, A. D., \& Patrick, F. (2006). Professional development and inquiry. London: Sage Publications.

Fullan, M. G. (1992). Successful school improvement: In the implementation perspective and beyond. Buckingham: Open University Press.

Good, T. L., \& Brophy, J. (2008). Looking in classrooms. (10th ed.). Boston: Pearson.

Gough, B. (1997). Teachers' centers as seen through the pages of the British journal of inservice education. British Journal of In-Service Education, 23(1), 23-30.

Guskey, T. R., \& Huberman, M. (Eds.). (1995). Professional development in education - New paradigms and practices. New York: Teacher College Press.

Hawkins, R. J. (2002). Ten lessons for ICT in the developing world. In S. Dutta, B. Lanvin, \& F. Paua (Eds.) Global Information Technology report 2004-2005, World Economic Forum, Oxford University Press.

Hendricks, C. (2006). Improving schools through action research. Boston: Pearson.

Inoue, Y., \& Bell, S. (2006). Teaching with educational technology in the 21st century: The case of the Asia Pacific region. London: INFOSCI.

Janssens-Bevernage, A., Cormille, B., \& Mwaniki, N. (2006). Integrating ICT in teacher training: A case study of the learning resource centre at the Kenya Technical Teachers' college. In F. Etta \& L. Elder (Eds.). At the cross roads: ICT policy making in East Africa. Nairobi: East African Publishers/IDRC.

Jones, N. (2007). Assessment and the national languages strategy. Cambridge Journal of Education, 37(1), 17-33.

Jung, I. S. (2005). ICT: Pedagogy integration in Teacher training: Application cases 
worldwide. Educational Technology and Society, 8(2), 94-101

Kendrick, M., Jones,S., Mutonyi, K. \& Norton, N. (2006). Multimodality and English education in Ugandan schools. English Studies in Africa, 49(1), 95-114

Kobia, J.M. (n.d). The challenge of mother tongue education in Kenya. LWATI: A Journal of Contemporary Research, 4, 30-

MacLeod, G. (2007). The quality of teacher education: Towards a research agenda in East Africa. A seminar paper presented at Aga Khan University, Institute of Higher Education, February, 2007.

Ministry of Education and Vocational Training (MOEVT) (2007). Medium term strategic plan, 2007/08-2009/10. Dar es Salaam.

Ministry of Education Science and Technology (MOEST) (2004). Teacher education syllabus. Volume 2. Nairobi: Kenya Institute of Education.

Mhaiki, D.I. (2009) Teacher Educators' Experiences in implementing the 2007 Teacher Education Diploma Curriculum: A Case Study of a Public Teachers' College in Tanzania. An unpublished dissertation submitted to the Aga Khan University, Institute for Educational Development, East Africa. Dar es Salaam.

The National Commission on Teaching and America's future (1996). What Matters Most: Teaching for America's Future. New York: The National Commission on Teaching \& America's Future.

Ngondu, S. A. (2010). Licensed teachers and the process of professional development. In UNESCO National Commission of the Republic of Tanzania, Tanzania and UNESCO Magazine, 6. 2009-2010.

Penny, A., Ward, M., Read, T. \& Bines, H. (2008). Education sector reform: The Ugandan experience. International Journal of Educational Development 28, 268-285.

Obama, B. (2006). The audacity of hope: Thoughts on reclaiming the American dream. New York: Crown Publishers.

Ong'ondio, C.O. \& Borg, S. (2011). 'We teach plastic lessons to please them': The influence of supervision on the practice of English language student teachers in Kenya. Language Teaching Research, 15(4), 509-528

Ponte, P. (2005). A critically constructed concept of action research as a tool for the professional development of teachers. Journal of In-service Education, 31(2), 24

Pritchard, A. (2005). Ways of learning: Learning theories and learning styles in the classroom. New York: David Fulton Publishers.

Putman, R., \& Borko, H. (2000). What do new views of knowledge and thinking have to say about research on teacher learning? Educational Researcher, 29(1), 4-15.

Rudney, G. L. \& Guillaume, A. M. (2003). Maximum mentoring: An action guide for teacher trainers and co-operating teachers. Thousand Oaks: Corwin Press Inc.

Sachs, J. (2003). The activist teaching profession. Buckingham: Open University Press.

SACMEQ (2011). Country report. Retrieved 13th April, 2012, http://www.sacmeq.org/ education-kenya.htm

SACMEQ (2011). Country report. Retrieved 13th April, 2012, http://www.sacmeq.org/ education-uganda.htm

SACMEQ (2012). Country report. Retrieved 13th April, 2012, http://www.sacmeq.org/ education-tanzania.htm

Scottish Executive Education Department, (SEED). (2005). The impact of ICT initiatives in Scottish schools. Phase 3. Edinburgh: SEED.

Stallworth, J. (1998). Practicing what we teach. Educational Leadership, 55 (5), 77-79.

Swilla, I.N. (2009). Languages of instruction in Tanzania: Contradictions between ideology, policy and implementation. African Study Monographs, 30(1): 1-14

Thorsen, C. (2006). TechTactics technology for teachers. Boston: Pearson Education.

Townsend, T., \& Bates, R. (Eds.). (2007). Handbook of teacher education: Globalization, standards and professionalism in times of change. Dordrecht: Springer.

UNESCO (2001). Understanding and responding to children's needs in inclusive 
classrooms. A guide for teachers. Retrieved May 27, 2009, http://www.unesco.org/ education/educprog/sne

UNESCO (2005). EFA Global monitoring report: The quality imperative. Paris: UNESCO.

USAID/UNITY Project (2007). Certificate in teacher education proficiency for teacher educators. Kampala.

Wamakote, L., Ang'ondi, E. K., \& Onguko, B. (2010). East African governments investments in information and communication technologies for education: Matching policy to practice. Itupale Online Journal of African Studies, 2, 25-38.

Wanzare, Z., \& Ward, K. (2000). Rethinking staff development in Kenya: Agenda for the twenty first century. International Journal of Educational Management, 14(6), 265-275.

Wim, P., \& Lawler, M. (2007). Investing in ICTs in educational institutions in developing countries: An evaluation of their impact in Kenya. International Journal of Education Development using Information and Communication Technology, 3(1), 5-22.

Peter Kajoro is a lecturer in Mathematics Education and Teacher Learning at the Aga Khan University, Institute for Educational Development, Eastern Africa, PO Box 125, Dar-Es-Salaam, Tanzania. peter.kajoro@aku.edu

Hellen Nabututu Chirure holds a Masters in Education (Teacher Education) from the Aga Khan University, Institute for Educational Development, Eastern Africa and a Masters in Education degree in Educational Administration and Management from Moi University, Eldoret, Kenya. Her research interests are in teacher learning and professional development.

Irene Simiyu holds a Bachelor of Education (Arts) degree in English/Literature from the University of Nairobi, Kikuyu campus and has been a secondary school teacher and head of department, Languages for 13 years. She recently graduated with a Masters in Education (Teacher Education) degree from the Aga Khan University, Institute for Educational Development, Eastern Africa. Her research interests are in second language writing and teacher education. 